\title{
Formation of Entrepreneurial Climate as a Factor of Social and Economic Development of the Region
}

\author{
Galina Kocharnaya ${ }^{1 *}$, Oleg Divichenko ${ }^{2}$ and Inna Demenenko ${ }^{2}$ \\ ${ }^{1}$ Penza State University, Department of State Management and Regional Sociology, 308012 Penza, Russia \\ ${ }^{2}$ Belgorod State Technological University named after V. G. Shukhov, Department of Sociology and Management, 308012, \\ Belgorod, Russia
}

\begin{abstract}
The paper considers the formation of entrepreneurial climate in the conditions of social and economic development of the region. At present, one of the priority directions of social and economic policy of the region is the development of small businesses. In turn, the entrepreneurial or business climate acts as a paramount component of small business development. The study of the current state of entrepreneurial climate in the region makes it possible to define current problems of its development and ways to solve them. The social mechanism of entrepreneurial enterprise climate formation in the region is directly focused on the formation of certain motives, ideas, behavior patterns of all business subjects (business community and authorities). This is revealed through the following principles: state support, priority objectives, equal conditions, diversification, partnership, social responsibility, social protection, public representation, exchange of experience, competitive advantage. For successful formation of entrepreneurial climate in the sphere of small business as a factor of social and economic development in the region it is critical to use such methods as monitoring, ranking, public-private partnership, business partnership, social support, multilevel training, multi-purpose competition, social selection, social cooperation in order to ensure interaction of small enterprises based on the principles of mutual aid, transparency and autonomy.
\end{abstract}

\section{Introduction}

Transformations of the 1990s in Russia provoked public attention to entrepreneurship as to an important source of social and economic development of a society. At the same time small and medium businesses existing in the economy along with large enterprises possessing a number of specific characteristics represent particular importance thus in many respects defining the welfare of the society in general [1].

Despite the fact that in international and domestic science and practice considerable attention is paid to problems of development of small business, many issues still remain unresolved. They are particularly acute for Russian scientists since the sector of small entrepreneurship in the country has already for quite long been in the condition of stagnation, which is illustrated by quantitative and qualitative indicators. The formation of favorable entrepreneurial climate is key especially for a small business as the most vulnerable sector of economy demanding state support. With regard to entrepreneurial climate of modern Russia, the most difficult situation remains in terms of weak protection of property rights, excessive burden of state regulation, preservation of administrative barriers, corruption, high and unstable taxation, weak competition, unreliability of personality protection, low level of corporate culture. It is not surprising that Russia does not hold top positions (from 91 and below) in the Best Countries for Business annual ranking prepared by authoritative international organizations. For this reason, the formation of entrepreneurial climate as a factor of social and economic development of the region is a relevant task and a vector of development for regional governance [2].

\section{Literature review}

Until the end of the 1980s the study of entrepreneurship was really popular (due to lack of the subject of study). 1980s-1990s were marked by a great number of search and descriptive studies of entrepreneurship, which main objective was to find key characteristics of a new social group - entrepreneurs. The study of the 2000s are characterized by complex methodological approaches. The increasing attention is paid to the analysis of internal and external factors influencing the development of entrepreneurship.

Methodological problems of business activity, features and tendencies of its development in general and in certain Russian regions were thoroughly considered by R.M. Akhmetshin and G.Yu. Vlasov [3, 4].

The issues of interaction of small businesses and authorities, social partnership, overcoming administrative barriers and such negative phenomena as

* Corresponding author: inna12manager@gmail.com 
"shadow" relations, raiding, and corruption were considered by L.S. Anikin, E. Galitsky, A.L. Kuzevanova [5, 6, 7].

Sociocultural aspects of business, value and motives of businessmen were deeply disclosed in the works of I.V. Bazylev, G.B. Kosharnaya, L.V. Orlova [8, 9,10].

The analysis of entrepreneurial climate, its state and dynamics in modern Russia and its certain regions, the influence of entrepreneurial climate on the management style at macro and micro levels were studied by V.A. Astafyev and L.I. Bestayeva [12, 13].

The role and place of entrepreneurship in modern Russian society, models of interaction between business and authority in the conditions of modern Russia were disclosed in the study of domestic sociologists - T.I. Zaslavskaya, V.V. Radayeva, A.Yu. Chepurenko [14, $15,16]$.

Admitting substantial contribution of scientists to the study of entrepreneurship and its climate, it should be noted that the issues related to the formation of social mechanism of entrepreneurial climate, methodology of its study and assessment, alongside with formation conditions and factors still require additional research.

\section{Instrument}

Within the study of conditions and problems of entrepreneurial climate regarding small businesses the authors conducted a survey of businessmen of the Belgorod region $(\mathrm{N}=289)$. The field study took place in July-September, 2017. The sampling population made 289 respondents. Main variables of entrepreneurial climate in the region: relationship between business and authorities, relationship within a business community, relationship between business and society, and selfconception of businessmen were studied. The choice of indicators is bound to questions within the social survey.

The sampling population represented the following social and demographic groups. By gender: men $65.12 \%$, women $-34.88 \%$. By age: under 30 years of age $-29.87 \%$, above 30 years of age $-30.87 \%$.

\section{Findings and discussion}

The term "climate" has long ago went beyond the natural science and is widely used in social sciences and humanities: in psychology - "psychological climate", in ethics - "moral environment", in sociology - "social climate", etc. Since the end of the 1980 s of the last century the term "entrepreneurial climate" implying a certain condition of an object under interest has been actively applied, in other words, the condition of factors exercising positive or negative impact. Hence, the notion of "entrepreneurial climate" covers characteristics of a system of factors within entrepreneurship activity.

In theory and practice of management, the "entrepreneurial climate" goes together with such concepts as business climate, investment climate, innovative climate, etc.; and, some authors identify them, at least entrepreneurship and innovative climate, while others distinguish between them [11]. In present interpretation the specified "climates" differ depending on what they belong to: investment climate - to conditions and factors of investment activities, business climate - to conditions and factors of business relations, entrepreneurial climate - to conditions and factors of entrepreneurship activity, etc. At the same time, the specified concepts are interrelated and their distinction is more an emphasis of separate aspects of organizational and managerial activity.

The majority of scientists and practitioners describe the "entrepreneurial climate" with more traditional terms: "entrepreneurship conditions", "entrepreneurship factors" [17]. Perhaps, for the assessment and description of cases under study such difference is insignificant, but if there are cases where it is necessary to give a more precise definition of entrepreneurial climate and even solve the issue of its targeted formation, then it is important to ensure semantic dissociation of related concepts and thereby specify the substantial trajectory of managerial actions. The authors identified several major differences between "entrepreneurship conditions", “entrepreneurship factors" on the one hand, and "entrepreneurial climate" on the other.

1. Entrepreneurial climate does not include all conditions and factors but only those which are significant for proper functioning and development of entrepreneurship.

2. Entrepreneurial climate defines certain integrity based on required and sufficient conditions (factors) of entrepreneurship. Not all conditions and factors belong to this integrity but only those which are required separately and sufficient cumulatively. The entrepreneurial climate is a system, and entrepreneurship conditions represent separate elements of this system.

3. Entrepreneurial climate is a sustainable state of conditions (factors) of entrepreneurship and their interaction.

4. At the same time, entrepreneurial climate is quite flexible and dynamic phenomenon changing depending on internal and external circumstances. At the same time, certain conditions (factors) can be invariable for a long time, and the entrepreneurial climate may repeatedly change during the same period.

5. Influence of conditions (factors) can be direct (straight) or mediated (indirect). The entrepreneurial climate is the system of conditions (factors) of direct influence.

6. Entrepreneurial climate covers modernized conditions and factors, i.e. their manifestation in potential (possible) and current state.

7. Entrepreneurial climate is characterized by "transparency" of perception and assessment, it correlates with high level of sensitivity of businessmen and other relevant social subjects.

8. "Transparency" of entrepreneurial climate for perception provides an opportunity to trace and monitor it and if necessary to accept and implement the regulatory impact.

To evaluate the conditions of entrepreneurial climate there is a need to define exactly what to evaluate, i.e. what variables and how to evaluate, i.e. by means of 
what indicators. Answering the first question, let us take into consideration four types of relationship forming the content of entrepreneurial climate - relationship between business and authorities, relationship within a business community, relationship between business and society, and self-conception of businessmen. The choice of indicators is bound to questions in social survey.

In order to define the general conditions of entrepreneurial climate in the region, it was suggested to respondents to evaluate the entrepreneurship conditions created in the Belgorod region. More than a third of respondents evaluated these conditions as "good", nearly a half of respondents consider them "normal". Only $10.6 \%$ of respondents believe that such conditions are "poor" $(5.3 \%$ of businessmen found it difficult to express their position).

The survey did not reveal substantial differences in evaluations by men and women, as well as two age groups. At the same time, two significant circumstances shall be noticed. First, businesswomen and respondents above 30 years old turn to be more sensitive to evaluation of entrepreneurship conditions. Second, respondents of the senior age group (above 30) are more critical about entrepreneurship conditions than respondents from the youth group (under 30). Higher criticism may be caused by more diverse motivation and need and, hence, higher standards, as well as broader experience of both spatial and temporal contrasts.

At the same time, the second part of the assumption was not confirmed by the distribution of responses to the following question: "Whether such conditions are better in comparison with what is available in other regions".

Respondents from the youth group showed the maximum sensitivity to comparative evaluation of entrepreneurship conditions whereas $6.9 \%$ of the senior age group found it difficult to answer.

Regarding this question, all respondents may be roughly divided into four groups: "optimists" - possible answers: "obviously better", "rather better"; "moderate" - possible answers: "the same"; "pessimists" - possible answers: "rather worse", "definitely worse"; "indifferent" - possible answers: "found it difficult to answer". It turned to be that the "optimists" represented the majority among men and young people; "pessimists" - among women and the senior age group; "moderate" among women and the youth age group; "indifferent" among men and the senior age group.

Generally, people tend to be not only presentoriented but future-focused when along with everyday plans they take into account long-term perspectives. In this regard, the issue of changing the entrepreneurship conditions, in other words, their direction, is becoming ever more critical.

Finally, the survey resulted in equal distribution of evaluations depending on gender and age of respondents. There are minor age differences among "pessimists" (their number is relatively higher in the senior age group) and "indifferent", which number is relatively higher in the youth group. It is probably more difficult for young people to evaluate the dynamics of entrepreneurship conditions than for the senior generation capable of a larger-scale temporal evaluation.
The prevalence of optimistic estimates of entrepreneurial climate in the Belgorod region is in line with its objective indicators. The results of the annual study conducted by the all-Russian public organization of small and medium businesses OPORA ROSSII (RUSSIA'S SUPPORT) demonstrate that the Belgorod region steadily appears among top ten advanced Russian regions on entrepreneurial (business) climate indicators. Certain indicators characterize it as one of the leaders in creating favorable conditions for the development of small and medium businesses. Since 2012, the Belgorod region holds top places in ranking on the creation of favorable administrative climate and safety. For comparison, the Lipetsk region on this indicator takes the 8th place, and the neighboring Voronezh region holds only the 37th place; and regarding "freedom from corruption" - 32nd and 22nd places respectively.

During the survey, the leaders of small enterprises made proposals to federal authorities on the improvement of the tax legislation: more than $30 \%$ of small business suggest providing businesspersons with the free choice of taxation, $55 \%$ of businesspersons supported tax decrease. At the same time, $60 \%$ of respondents consider the unified tax on imputed income for separate kinds of activity as the most acceptable form of taxation.

The leaders of small enterprises prefer the relationship with authorities in the following forms (\%):

- direct business contacts -57.6 ;

- participation in conferences, meetings, round tables $-57.0$

- interactions through business communities - 11.0;

- written requests, etc. -33.0 .

According to the survey, the quality of cooperation with small and medium business support organizations depends on the following factors (\%):

- variety of provided services - 11.5;

- quality of provided services - 13.8;

- staff service - 7.6;

- convenience of paperwork -12.5 ;

- others -4.3 .

The respondents also noted a number of factors preventing the interaction of businessmen with small and medium business support organizations, namely (\%):

- there is not enough information on these organizations -29.3 ;

- activity profile of these organizations does not match the requirements -6.9 ;

- quality of services provided by these organizations is very low -4.0 ;

- inconvenient geographical arrangement of data of such organizations -8.2 ;

- other - 2.0;

- noted that there are no such reasons -43.8 .

The activity in the sphere of business and efficiency of this activity depend in many respects on the relation of people around - positive, neutral or negative, which is illustrated by the status value of entrepreneurship activity.

The social survey of businesspersons of the Belgorod region showed that people around $(69.6 \%$ of respondents) are generally positive to their activity. 
There were no significant differences in answers of men and women. At the same time, the following attracts attention: among female respondents there are more of those who believe that they treat their business activity "differently", and among male respondents there are more of those for whom it was difficult to answer. The same may be applied to age differences. Among entrepreneurs of the senior generation there are more opinions regarding the fact that they are treated "differently", while young businessmen found it difficult to answer.

Considering the indicators of social wellbeing (selfconception) of businessmen, it should be noted that three quarters of respondents engaged in entrepreneurship activity were satisfied with the results of such activity. At the same time, the satisfaction or dissatisfaction of a person with results of business performance depend on many factors, but one of them undoubtedly deserves special attention. This is the success achieved by the person. The specified dependence may be expressed regarding activities that bring some result and hence satisfaction. Answers of respondents in this respect present particular interest: regarding the question "Whether you succeed in your business?" every seventh respondent answered unambiguously "yes, definitely", $45 \%$ - "almost", 25.8\% - "sometimes". Only 4\% of respondents said that "nothing is impossible" and 10.6\% found it difficult to answer the question.

The obtained data confirm that there is more optimism regarding business results among female entrepreneurs and businessmen from the senior age group. It is possible that in the first case it is caused by modest commercial ambitions of female entrepreneurs and hence higher satisfaction; in the second case - by real achievement of commercial and other success typical for businessmen from the senior group.

In the conditions of limited material and financial resources, motivation is perceived as the most important factor of entrepreneurship. The key to motivation is to strengthen its impact not so much on proliferation of small businesses but on the increase in business activity of entrepreneurs. "However it should be noted that the issue of entrepreneurship motives is extremely difficult to analyze since motives are not always accurately fulfilled by a person, but are surely endured as something significant, valuable, i.e. motives are closely connected with individual values".

The study was separately devoted to objectives and motives of starting a business. According to social survey, the main objective is to gain high income. Both acting and emergent businessmen point to this fact. The second category of respondents is even more focused on gaining high income than the first category. Most likely, this focus becomes more moderate over time. Then there are such motives as "financial independence", "unwillingness to work under someone's authority", "desire to be the owner of your business".

Every seventh or eighth respondent comes to business due to job loss. Self-realization motives being part of a family business are also remarkable.

Other objectives and motives play a relatively smaller role. Let us pay attention to one of them, i.e. "opportunity to implement innovative ideas". Every ninth of emergent entrepreneurs is aimed to implement innovative ideas, which confirms the corresponding innovative potential of small businesses. However, with time this aspiration gets weaker or is absolutely lost.

Currently, according to survey results, three key and equivalent problems interfere with business activity in Russia: sales slowdown, lack of qualified staff and price/tariff increase. Tough situation for years remains in such spheres as weak property rights protection, lack of independence and bribability of courts, corruption, excessive burden of state regulation, unreliability of personality protection, low level of corporate culture, weak competition, administrative barriers, high and unstable taxation.

The analysis of entrepreneurial climate in the Belgorod region and other Russian regions allowed identifying 8 groups of urgent problems of its development:

- growth of small business;

- optimization of relations between business and authority;

- fair competition;

- safety of small business;

- corruption;

- optimization of relationship between small business entities;

- insufficient motivation;

- increase in social responsibility.

It should be noted that targeted formation of entrepreneurial climate as a factor of social and economic development of the region ensures, first of all, justification and formulation of certain principles of both initial and major requirements to the implementation of such targeted activity.

\section{Conclusion}

Thus, within the study of entrepreneurial climate as a factor of social and economic development of the region, following conclusions can be made:

1) majority of entrepreneurs positively assess the role of regional administration in support of small businesses. The systems of grants, credit assurance, pledge funds, etc. are gaining more ground;

2) business success is defined by both external and internal factors. Most respondents consider that business success depends on them (exclusively or generally). A certain part also counts on governmental support, every tenth is focused on favorable concurrence of circumstances. Direct social environment also favors the business activity. The family and friends of businessmen render financial, psychological, and moral support;

3) analysis of social problems regarding the entrepreneurial climate results in the need to identify eight the most important and relevant problems.

Efficient use of entrepreneurial climate potential at the regional level is caused by regulation conditions. In turn, this is possible under compliance of certain initial and major requirements to this activity. Among them are the principles of state support, primary objectives, equal 
conditions, diversification, partnership, social responsibility, social protection, public representation, exchange of experience and competitive advantage. Thus focusing on favorable entrepreneurial climate these principles imply the choice of target priorities in small business development and ensure equal access of all businessmen to state support.

\section{References}

1. A.Yu. Andriyanov, D.A. Grekhova, Creative economy 83, 83-87, (2013)

2. F. Jacob, Industrial Marketing Management 35, 1, 45-56 (2006)

3. R.M. Akhmetshin, Russian business 22, 220, 38-41 (2012)

4. G.Yu. Vlasov, Russian business 6, 44-50 (2011)

5. L.S. Anikin, Bulletin of Saratov University. New series. Series: Sociology. Political science 2, 31-33 (2012)

6. E. Galitsky, Issues of economy 1 (2007)

7. A.L. Kuzevanova, Scientific prospect 11, 92-96 (2010)

8. I.V. Bazylev, Etnosocium 9, 51, 128-134 (2012)

9. G.B. Kosharnaya, Bulletin of higher educational institutions. Volga region. Social sciences 4, 36, 146-154 (2015)

10. LV. Orlova, Sociological Model of Business Space of a Russian Businessman" Human Resources and Intellectual resources management in Russia. (M.: INFRA-M) 1, 16, 65-69 (2015)

11. I.A. Gulei, O.A. Smolenskaya, I.V. Shavyrina, V.A. Shapovalova, Journal of Advanced Research in Law and Economics 6, 3, 551-559, (2015)

12. V.A. Astafyev, Economy and business 9, 329-334, (2014)

13. L.I. Bestayeva, Economy and business 8, 1119-1122 (2015)

14. O. Zaslavskaya, Expert channel Economic policy (2013)

15. V.V. Radayev, Political study 5, 79-87 (1993)

16. A.Yu. Chepurenko, Entrepreneurship sociology. (M.: Publishing house of HSE, 2007)

17. Z.N. Avilova, I.A. Gulei, I.V. Shavyrina, Mediterranean Journal of Social Sciences 6, 3, 207$216(2015)$ 